\title{
ASSESSING THE AUTHENTICITY OF THE STUDENT LEARNING EXPERIENCE
}

\author{
Bissett-Johnson, Katherine Mary (1); Radcliffe, David F (2) \\ 1: Swinburne University of Technology; 2: Purdue University
}

\begin{abstract}
Authentic learning is an approach to teaching where the learning is embedded in a real world context, in real situations or simulations, and offers students opportunities for problem solving challenges much like they will encounter in real life. This paper discusses and reflects upon the development a course designed to teach Socially Responsible Design approaches, methods and tools to Product Design Engineering students using global projects. Our research question was to investigate if this Socially Responsible Design course, it's structure, delivery, learning activities and assessments combined to deliver an authentic learning experience. Through informal interviews with staff, review of student reflections, review of university student feedback comments and consideration of final outcomes, all within the framework of Herrington and Oliver's nine elements of authentic learning, we found that this course did provide an authentic learning experience for many reasons. This study offers academics a frame work for reviewing existing and future courses with a view to creating or enhancing authentic learning experiences using project based learning
\end{abstract}

Keywords: Authentic Learning, Product Design Engineering, Social responsibility, Design education, Design methods

\section{Contact:}

Bissett-Johnson, Katherine Mary

Swinburne University of Technology

Architectural and Industrial Design

Australia

kbissettjohnson@swin.edu.au

Cite this article: Bissett-Johnson, K.M., Radcliffe, D.F. (2019) 'Assessing the Authenticity of the Student Learning Experience', in Proceedings of the 22nd International Conference on Engineering Design (ICED19), Delft, The Netherlands, 5-8 August 2019. DOI:10.1017/dsi.2019.48 


\section{INTRODUCTION}

A project-based course to teach Socially Responsible Design (SRD) was developed and delivered from 2008 - 2018 at Swinburne University of Technology, for 3rd year undergraduate Product Design Engineering students. To underpin the teaching of this course we defined SRD as having four intersecting elements: socio-cultural, environmental, economic and technological (Bissett-Johnson 2014). The course operated as a 4 hour per week studio class, a format that is more common in Industrial Design or Architecture, in which the students tackled projects that were situated in global contexts (predominately India) with real clients. The engineering students' design work was guided by a series of design methods, adapted to learning activities, based on the principles of human-centered design (HCD).

Service learning is the term often used to describe a pedagogy integrating academic learning with a focus on meeting human needs, often for underserved communities. Service Learning in design provides real-world experiences through direct engagement with users, developing multidisciplinary skills and building students' understanding of both process and awareness of users in their context (Brodeur 2013).

Professionally and educationally, human-cantered design therefore often involves face-to-face contact with users in their own context, however realistically within the weekly timetabled university context this is not always practical. Nevertheless, for the SRD course, the project was situated in a real context but remote from the class room, hence from an educational perspective, we were interested to investigate if this course, its structure, delivery, learning activities and assessments combined to deliver authentic learning experiences.

This paper provides an introduction to authentic learning, followed by a description of the SRD course. The study is based upon a reflection on this course through the lens of nine elements of authentic learning and concludes with a discussion of the findings.

\section{AUTHENTIC LEARNING}

Authentic learning is where students experience the problem-solving challenges replicating those in the real world. This is achieved by situating the learning in a real world context (Herrington et al., 2014). What counts as authentic learning has been characterised in several ways. For example, Rule (2006) identified four themes that are common across authentic learning:

- $\quad$ Real-world problems that engage learners in the work of professionals;

- Inquiry activities that practice thinking skills and metacognition;

- Discourse among a community of learners;

- $\quad$ and Student empowerment through choice.

Taking a slightly different approach, Strobel et al. (2013) identify the following four dimensions of authenticity.

- Context Authenticity: Does it resemble daily life experiences and does the activity involve a suspension of disbelief process, such as when watching a movie?

- Task Authenticity: Does it focus on constructivist type learning environments in which students may be challenged to make decisions in practical contexts?

- Impact Authenticity: Does the experience transfer to activities outside of school?

- Personal/Value Authenticity: Does it lead to self-exploration?

Both of these definitions offer a broad explanation as to what constitutes authentic learning, however based on a critical analysis of education research into authentic learning, Herrington and colleagues arrived at the framework presented in Table 1, which presents nine elements that are both interconnected and interdependent (Herrington and Oliver 2000; Herrington et al., 2014). All three approaches point to the multi-dimensional nature of an authentic learning experience. Although they use different terminology, the dimensions identified by Rule and by Strobel and colleagues can be mapped to each other and are contained within the more comprehensive framework proposed by Herrington and Oliver (2000). The nine elements in the Herrington and Oliver model therefore provide a convenient basis for a reflective review of the course developed to teach SRD at Swinburne University of Technology, Melbourne, Australia. 
Table 1: Nine elements of authentic learning (Herrington and Oliver 2000).

\begin{tabular}{|c|c|}
\hline Authenticity Element & Summary Description \\
\hline Authentic context & $\begin{array}{l}\text { Reflects the way the knowledge will be used in real life; needs to be all- } \\
\text { embracing, to provide the purpose and motivation for learning, and to } \\
\text { provide a sustained and complex learning environment that can be } \\
\text { explored at length }\end{array}$ \\
\hline Authentic tasks & $\begin{array}{l}\text { Ill-defined, requiring students to define the tasks and subtasks needed to } \\
\text { complete the activity; are investigated by students over a sustained } \\
\text { period of time; can be integrated and applied across different subject } \\
\text { areas and lead beyond domain-specific outcomes; are seamlessly } \\
\text { integrated with assessment; create accomplished products valuable in } \\
\text { their own right; and allow competing solutions and diversity of outcome }\end{array}$ \\
\hline Expert performances & $\begin{array}{l}\text { Provide access to expert thinking and the modelling of processes, access } \\
\text { to learners in various levels of expertise, and access to the social } \\
\text { periphery or the observation of real-life episodes as they occur }\end{array}$ \\
\hline $\begin{array}{l}\text { Multiple roles and } \\
\text { perspectives }\end{array}$ & $\begin{array}{l}\text { Enable and encourage students to explore the task from different } \\
\text { perspectives, considering various points of view, and to "crisscross" the } \\
\text { learning environment repeatedly }\end{array}$ \\
\hline $\begin{array}{l}\text { Collaborative } \\
\text { construction of } \\
\text { knowledge }\end{array}$ & $\begin{array}{l}\text { Tasks need to be addressed to a group rather than an individual, and } \\
\text { appropriate means of communication need to be established }\end{array}$ \\
\hline Reflection & $\begin{array}{l}\text { An authentic context and tasks facilitate meaningful reflection that } \\
\text { enable abstractions to be formed. These also provide nonlinear } \\
\text { organization to enable students to readily return to any element of the } \\
\text { learning environment if desired, and the opportunity for learners to } \\
\text { compare themselves with experts and other learners in varying stages of } \\
\text { accomplishment }\end{array}$ \\
\hline Articulation & $\begin{array}{l}\text { Tasks need to incorporate inherent (as opposed to constructed) } \\
\text { opportunities to articulate, collaborative groups to enable articulation, } \\
\text { and the public presentation of argument to enable defence of the position }\end{array}$ \\
\hline $\begin{array}{l}\text { Coaching and } \\
\text { scaffolding }\end{array}$ & $\begin{array}{l}\text { Provide collaborative learning where, for example, more able partners } \\
\text { can assist with scaffolding and coaching, and where teachers provide } \\
\text { appropriate learning support at critical times }\end{array}$ \\
\hline Authentic assessment & $\begin{array}{l}\text { Opportunity for students to demonstrate their effective performance with } \\
\text { acquired knowledge, and to craft polished, performances or products in } \\
\text { collaboration with others. Assessment should be seamlessly integrated } \\
\text { with the activity, and to provide appropriate criteria for scoring varied } \\
\text { products }\end{array}$ \\
\hline
\end{tabular}

\section{THE STUDY}

All courses change over time in response to multiple influences of staff, university demands, student feedback and changing industry expectations. Often there is little chance for reflection and analysis from different perspectives. This study reflected on the latest variant SRD course using Herrington and Oliver's (2000) nine attributes for authentic learning. The reflection was based on informal interviews with teaching staff, review of student project outcomes, student feedback surveys and a simple analysis of student reflective texts where common themes were drawn out and categorised.

\subsection{The details of the SRD course}

Using a studio class typology, which has an extended class time of 4 hours $(2 \times 2$ hour sessions) per week with specific learning activities in each session, the SRD course runs once per year for 12 weekly sessions. Sitting in second semester of the third out of minimum four years in the curriculum of Product Design Engineering, this course is the second design studio in 3rd Year and is expected to prepare students for their Honours research project by providing a problem setting and research-based design experience. Generally, this course has a relatively small cohort of between $12-24$ students per 
class. Each year two staff co-teach this course, one from an Industrial Design background and one practicing engineer, to provide comprehensive supervision and feedback to the students. The content and learning scaffold were developed by both staff, representing a cross-disciplinary approach, additionally ensuring that the outcomes represented essential skills for both Industrial Design and Engineering professions (as Product Design Engineering is a cross disciplinary course with employment prospects in either discipline area).

The main objective of the course is to bring a human-centric approach into this particular Product Design Engineering studio by teaching SRD. Whilst this may appear a simple mandate, teaching students how to undertake human-centered design as a way to address social issues yet facilitating the design and engineering of a product outcome requires careful consideration. Founded on a simple of model of SRD as being "good" for people and "good" for the environment, students are required to consider the problem and solution within four elements of SRD being socio-cultural, environmental, economic and technical influences.

All of the design briefs/fieldwork data for the course between 2008 and 2018, were globally derived and located, predominantly in developing countries and provided from real clients such as NonGovernment Organisations, charitable organisations and more recently from the Honey Bee Network in India (Network 2018). Whilst students are not able to visit users/clients face-to-face, the fieldwork and problem scenarios provided by these international organisations are real issues from an expert's perspective, and at the end of the project these organisations were able to provide critical feedback to staff on the suitability of final solutions. The clients' willingness to continue working with the staff and new cohorts of students over many years is testimony to suitability of the resultant outcomes.

In response to feedback from clients, students and other staff, the course has been continually enhanced and refined, despite the fact that this was never part of a master plan, the refinement has been reflexive. The nature of the design problems and scenarios from clients has evolved over time from being at first quite prescriptive to in later years increasingly derived from interview findings done by local organisations with real users. More details of the course are described in (BissettJohnson 2014, Bissett-Johnson 2016).

\subsection{Course structure and design methods tools as assessable tasks}

For the purposes of this study we have chosen to write about the latest variant of the course, as early variants have been analysed, discussed and documented elsewhere (Bissett-Johnson 2014, BissettJohnson 2016). The SRD course commences with investigation and analysis of the fieldwork provided by international clients leading into guided fact finding desk research. A series of learning activities were created based on the HCD techniques, methods and tools developed by IDEO (Ideo.org 2015). These design methods needed to be converted to learning activities to make the learning explicit and assessable (see section 4.1 for some examples and Figure 1 for an explanation of where the learning activities sit in the course). Also, these techniques are generative and creative and thus importantly underpin and support the design process, for example, IDEO's Sacrificial Concept helped to frame the preferred problem and its attributes or a Value Proposition for the final concept clearly linked the designed solution with priorities of the of the original problem. The course was designed such that the learning activities reflected and were incorporated into the design process where findings from learning activities influenced and moved the design outcome from a general idea to a specific and detailed product. Various more traditional communication modes were used as a part of the design process such as sketching, mock-ups, verbal presentations, prototypes and engineering documentation, additionally other activities also guided students to develop business plans and to consider the social and environmental impact of the potential implementation of their product, thus addressing the four elements defining SRD which underpinned the course.

The project ran for 12weeks and was comprised of four stages (see Figure 1), following the wellknown double diamond design process (Design Council 2015), with different learning activities in each stage. 


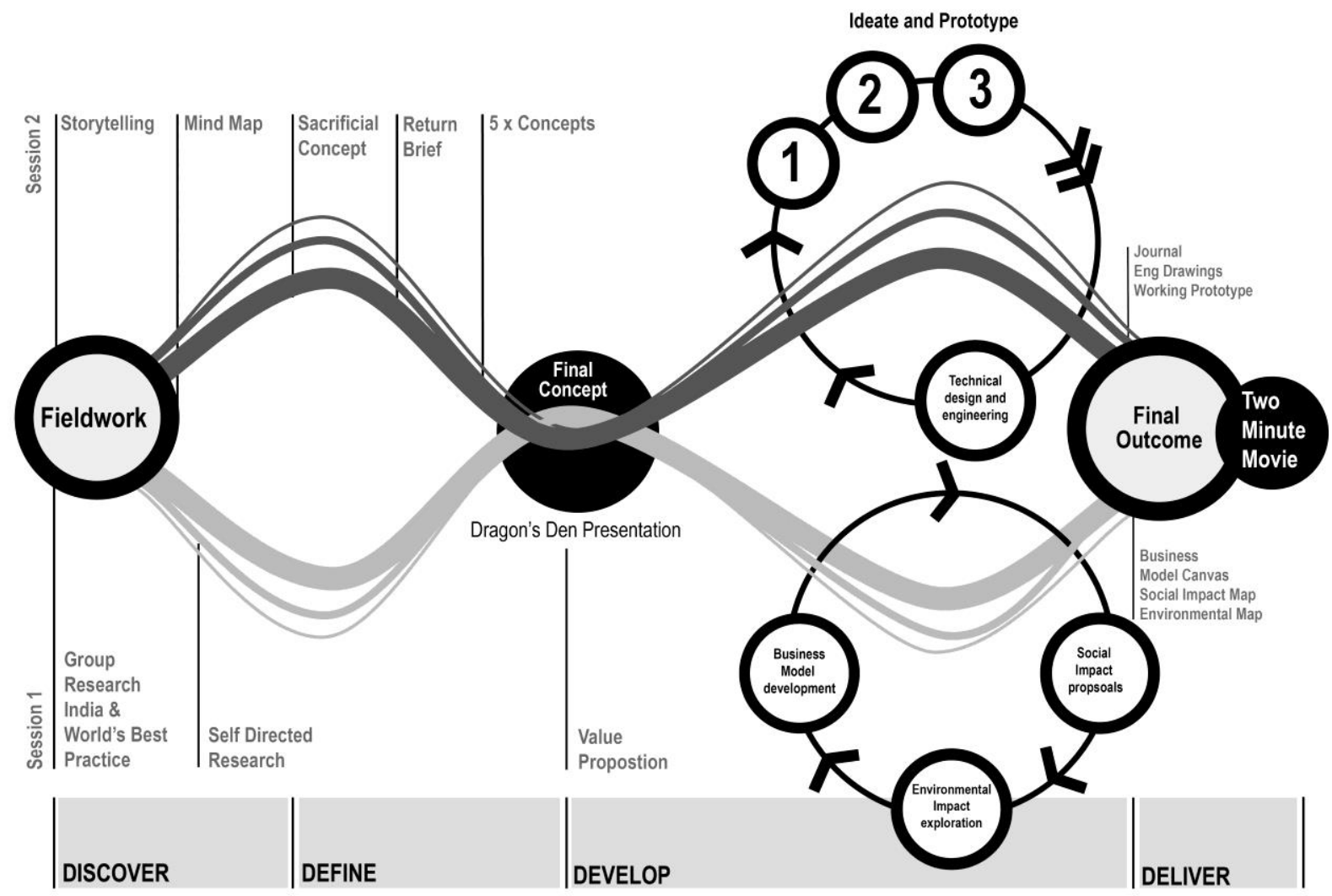

Figure 1: Learning activities within the four stages of the double diamond design process. This diagram is given to students as course map at the beginning of the project so that they understand where each of learning activities intersects with the design process.

\section{FINDINGS}

The nine elements in Herrington and Oliver (2000) framework are interconnected and interdependent and provide a sufficiently detailed basis for either designing authentic learning activities in a new course or for assessing the authenticity of experience in an existing course. The following sections present a reflective stance on the findings of the analysis.

\subsection{Authentic context}

Whilst the clients were located outside of the classroom, several steps were made so that the students would experience complex design problems in a fashion similar to that of a professional who was using a human-centered approach working with an underserved community, thus following the pedagogical model for service learning as defined by Brodeur (2013). The design projects in the course always required consideration of not only the technical aspects but also the prevailing sociocultural, environmental and economic conditions, the four elements of SRD. The students had access to authentic fieldwork data, online (including reports, transcriptions of interviews and videos of the user in context) derived from the clients' direct interactions with the user/local community and university staff "stood-in" to debate and answer direct questions arising from investigation of this fieldwork. Therefore, we argue that this approximates to an authentic context, despite the limitation of limited direct access to users, it is clear from student feedback that they were clearly motivated by the genuine setting of the problem. Achieving such a degree of 'buy-in' by the students is telling as a human-centered approach depends upon the designer generating a degree of empathy for the user. By immersing the students in the context for the problem in an authentic way, they were able to move towards reviewing their solutions from the user's perspective, developing an empathic approach, understanding the content in a deeper manner and thereby broadening their critique to include the social and sustainable aspects and shift further from only a technical review (Cardella, Zoltowski \& Oates 2012). 
To further enhance this sense of authenticity, several of the design method tools were modified to increase the focus on social, economic and sustainable aspects of problems. This included:

1. Business Model Canvas with Social Impact, adapted from (Osterwalder et al., 2010)

2. Cradle to Cradle diagramming considering the local supply chain and local materials, (adapted from McDonough and Braungart 2002)

3. Story-telling, and a day in the life of the user told from a first-person perspective, (School 2008)

4. Adapted Ideate and Prototype Tool (Bissett-Johnson 2014, Bissett-Johnson 2016)

5. Social Impact Map created by author (Bissett-Johnson 2014)

6. Adapted Sacrificial Concept (Ideo.org 2015, Bissett-Johnson 2014, Bissett-Johnson 2016)

Below is a quote from the Swinburne University student survey, showing the influence of the authentic context on engagement and learning. "The unit is highly engaging and has some eye opening content. Really helps to consider so many aspects involved with design and the fact that design can be really satisfying when helping out communities and certain people."

\subsection{Authentic tasks}

The course commences with an interrogation of client fieldwork, we argue this provided an example of an authentic task as the problem was ill-defined and therefore the student needed to use generative design methods to establish the project design brief and determine influential design criteria from the four elements of SRD (socio-cultural, economic, environmental and technological influences). This activity broadens the focus from purely technical solutions and as such, depending the prioritisation of these criteria by each individual student, allowed for competing solutions and reinforcing design decision making. Further to this, beyond domain aspects such as the development of a business canvas with social impact, students were required to describe how the product may reach the user, with options such as donation, leasing, Do-it-yourself assembly, training of the local community, co-ops and microfinancing to be explored and thus directly influencing the manufacturing, production and assembly of the final product. Complexity and ill-defined problems were disorientating for students whose previous engineering studies may have been based on clearly defined right and wrong answers in engineering subjects and more tightly constrained problems and requirements in design studios. Clear guidance and mentoring were required to increase the chances that learning activities would indeed help the student to find a creative answer. Product Design Engineering students exhibited some difficulty in coping with the need to make working assumptions, or early approximations so as to get started and they resisted the need for constant iteration, even though these are essential aspects of design practice; in short, they found this way of thinking and working extremely challenging. Undertaking these types of projects in professional practice requires these skills and mind-sets to solve complex ill-defined problems thus these skills and mindset are incredibly important in preparing future-ready learners.

A diversity of potential suitable solutions and thus competing solutions, was seen in the recent version of the syllabus where a project was undertaken that focused on fieldwork supplied by the client in India relating to Potter communities. The fieldwork identified that filtering the clay was a major health issue. Several Students designed clay filtering products that removed that risk, each student utilising a different technique to filter such as a hand lever, gravity, centrifugal, Archimedes screw, etc., thus offering multiple solutions for the same problem (see Figure 2). However, each solution responded to different design and engineering criteria in respect to clay filtering technique, scale, material construction and how the solution could be integrated into the Potter's general process of clay collection and preparation.

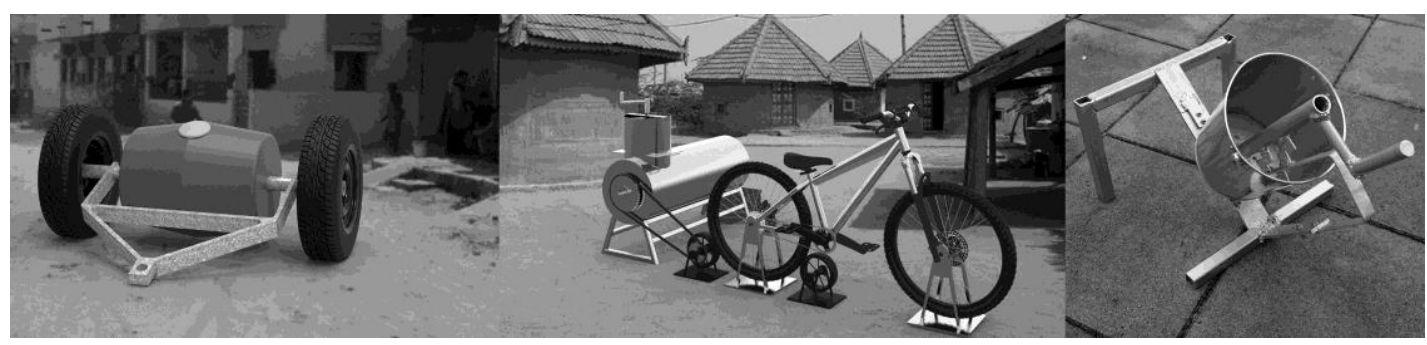

Figure 2: Examples of multiple possible 'competing' solutions, each with a different emphasis, scale and method of operation to perform the same function of filtering clay. 


\subsection{Expert performances}

As the open-ended projects were coupled with the generative nature of HCD design methods, there was not one 'right answer', so teachers were on the spot to encourage, discuss and mentor students with this new way of thinking. This immersive experience with a range of expertise from two disciplinary perspectives created social, fluid and emergent interactions and presented opportunities for highly relevant stories from practice. An example of this was one of the most influential stages of the project, the adapted ideate-prototype process, where staff assisted in planning for iterative prototyping and testing, demonstrating how the process could be used to refine an idea. The tool had been adapted to include the constraints of using culturally familiar, easy to access local materials, to use accessible manufacturing processes and to consider reduced environmental impact (Bissett-Johnson 2016). Students were required to research specific regions in India and to specify local materials, local suppliers and use readily accessible manufacturing processes based on these findings.

\subsection{Multiple roles and perspectives}

The pedagogical basis of the course, the four elements of SRD is one that explicitly focuses the students' attention on multiple perspectives in their approach to design and engineering. In the very structure and operation of the course they are constantly reminded of the need to address the technical, social, environmental, economic aspects in a balanced fashion, appropriate to the particular project circumstances. The final outcome must be delivered in terms of a technical solution combined with clear evidence of consideration of the social, economic and sustainable impacts. This emergent outcome is reviewed multiple times throughout the course, from multiple viewpoints, consistently returning to the SRD four elements. Successive guided staff and student reviews of the project, force students to consider how the product might enhance the lives of the users or the broader local community and to consider indepth what the social implications of the introduction of the product might be on a community. The students are supported in adopting a multiple perspective approach, being introduced to a variety of design methods each with a focus on a different one of the SRD elements. Evidence of the application of these design methods was also evaluated as a part of the summative assessment Rubric in addition to formative reviews.

\subsection{Collaborative construction of knowledge}

A core value embedded in the course is the cultural expectation that permeates the operation of the studio environment, that of peer review of work based on constructive criticism. This not only holds students accountable for their work but also makes ideas public and thus aids the co-construction of knowledge about the project, developing a shared understanding of the context and the issues. While the students each produce an individual solution in response to the given project in any year, they are grouped by themes or communities, so that they become experts about a particular theme or community and are empowered to act as experts in reviewing outcomes and speculating on product impacts for specific communities. Sharing of information and research findings was an unexpected outcome of the peer review process, as was debate about the 'best' solution and the relative ranking and importance of particular design criteria in critiquing work in progress solutions.

Over time, this debate has become critical in driving the refinement of ideas and in the decision-making process particularly in the later stages of the project. A wide variety of techniques are used in the course to facilitate peer review, including the feedback capture grid (School 2008), small group reviews, and Dragon's den pitches (short pitch of problem and solution). The course also uses Pin-Up Critique, where individual students orally present a poster of their ideas or work followed by group Q\&A, on a regular basis throughout the semester. This not only facilitates comparison of ideas and knowledge co-creation around the project, but also improves the quality in communicative visuals and the defence of design and engineering ideas, as the students are actively encouraged learn from each other on how best to get ideas across.

\subsection{Reflection}

A reflective attitude is encouraged throughout this course through the oral public defence of the propositions at milestones, the in-class critiques and the reflective journal at the conclusion of the project documenting the design process, articulating design decision making and product resolution. The 
following quote from a Product Design Engineering student demonstrates how reflection can go further and provide greater insights than a simple statement of the steps of the project.

"Designing for a low-income community with a social responsibility aspect has also been very informative. I realise not everything I design is going to be a clean, shiny expensive product, there may be times where I'm needed to use second hand materials or products and produce something else from it. This is especially prevalent in our current global environmental stage: the lack of renewable resources should be a great motivation for more of this thinking. An attitude towards innovation in products that have social benefit is needed from all designers: we cannot just design products that have no greater value than aesthetics."

Aside from traditional written reflections, learning activities such as the compilation of a Two Minute Movie (see Section 4.7) foster reflection and a ranking of important parts of the project story in order to make sense of the narrative of the project from problem to solution, drawing out and connecting the most important aspects of each. Weekly discussion with staff and peers helped students develop their personal design and engineering practice through explanation and description of the progress of the design concept and definition of future steps required to complete the project. Thus, there are multiple instances and various mechanisms in the running of the SRD course through which students are able to try to find meaning and make sense of what they are doing beyond the immediate task at hand.

\subsection{Articulation}

Articulation, like reflection, is an ever-present learning activity throughout this course. Making use of diverse modes of communication such as; HCD design methods as learning activities, sketching, model making, oral defence, engineering documentation, value proposition statement, business model canvas etc, each mode revealing different aspects of the project. In this way the students acquire a multifaceted skill set on possible ways to communicate their ideas to different audiences in different settings. The project culminated in the production a Two Minute Movie containing content that described the problem and the solution, demonstrated the working product, and speculated on potential business, social and sustainable impacts. Students shared their Two-Minute Movie during the class time with the opportunity for comment and critique from their peers. The movie was a flexible format for the communication of the many different aspects of these projects, it also accommodated different communication modes such as animation, face to camera, still images or info graphics. Some students also creatively employed music to add to the narrative's emotive quality. Significantly, these movies were also shared with the international client for the project for feedback. Making the movie forced students to make choices about important aspects of the problem and the solution, and how best to communicate both the technical features and the subtle, more difficult to convey aspects of social and sustainable impact. Storyboarding for the movie also was an unforeseen reflective process.

\subsection{Coaching and scaffolding}

The studio mode of running this course means that the teachers were alongside the students at all times in the role of coaches, modelling expert performance and support for various learning activities designed to scaffold student learning. Through the mechanism of milestone deliverables and formative feedback throughout the stages of the design process, the students are guided in the application of many design methods. A pertinent example is the scaffolding method used to foster a sustainability mind set in the students through mapping materials usage and its lifecycle impact based on McDonough's Cradle to Cradle diagram (McDonough and Braungart 2002). Through this lens, students were able to identify and understand the supply chain in the local context and additionally to think cyclically and systemically in respect to the product lifecycle from raw materials to end of life. In developing countries such as India, these supply chains are important and quite different to those in western cultures, they can be seen to have social and environmental impacts are were thus very important to the project. Selecting a material or component with the least impact requires significant support from teaching staff. This process involves many conversations mediated through a series of Cradle to Cradle diagrams developed and refined by the student to explore and discover the influences on the end product and the impact of the supply chain for product and its construction. 


\subsection{Authentic assessment}

Assessment is integrated into the fabric of the course. Effective performance in addressing socio-cultural, environmental, economic as well as and technical aspects of the project form the basis of the assessment criteria for the course. Through the process of being coached and supported in learning how to use the various design methods, the students apply them to arrive at their project solution, and this results in assessable evidence of appropriate use of these methods. This evidence of performance accumulates across the course of the semester, through the various stages of the design process, and encompasses the four elements of SRD. Assessment thus focused on the learning of 'how to design' and not just on the attributes of the final product outcome. Not all students completed all of the tasks in depth, with some defaulting to a focus on the technical. However, to get a high overall score for the project, the students needed to address all of the four SRD elements by developing a holistic product proposal that was technically sound, socially, culturally and environmentally appropriate.

\section{DIscussion}

The experience of human-centred design is valuable for all engineering students as it highlights the complexity of technical problems and guides students to consider the broader impact of their technical decisions (Beder 1999, Brodeur 2013, Cardella et al., 2012). Project-based learning offers a good strategy for teaching HCD methods and processes and additionally, we argue, offers the opportunity to create authentic learning experiences enabling higher order learning. In reflecting on this SRD course, we found that the course structure, learning activities, approach and social studio class nature provided the attributes for an authentic learning experience. This can be summarised using the four dimensions of authenticity defined by Strobel et al., 2013.

Context Authenticity was achieved through the provision of real world fieldwork, open ended selfdirected projects, hands-on experience of using human-centred design methods and more traditional design and engineering skills and the use of the different modes of communication required to describe the resolution of the product proposal (Sketching, Prototyping, Social impact Map, Oral defence, Two Minute Movie etc). Immersion in the fieldwork allowed for a 'suspension of disbelief' as these were indeed real problems. Students' prior learning in the design studios had been far more structured with clearly defined questions and answers thus an open ended project was significantly more difficult requiring discipline modelling from staff in how to approach ill-defined problems.

Task Authenticity is evidenced by the course's real-world relevance, the learning of the importance of a human centric approach, the recognition of the impact of design and engineering on social, environmental and economic realms of any user and the requirement for students to constantly evaluate and interpret ambiguous data. The requirement for constant evaluation of the four elements of socially responsible design throughout the project also required more effort from students as the teachers mentored them in making informed decisions as opposed to making those decisions for them.

Sharing of the project outcomes both within the class room and with the external clients built student motivation and engagement and thus we argue is an example of Impact Authenticity. In addition, the linking of the learning activities to the design process promotes inquiry and a depth of investigation across the four elements of SRD. Those students who were high achievers in this course learnt to be flexible and take on board critique at milestones, developing a wiliness to incorporate changes in response to peer and staff criticism and refined their ability to defend their propositions and communicate the rationale for their design and engineering decision making.

Personal/Value Authenticity was revealed in the student reflections at the end of the project, detailing the experiences and challenges of working in new ways, such as tackling an ill-defined problems, learning new HCD methods or working through the adapted Ideate and Prototype process which often proved confronting and frustrating. Nevertheless, many students also commented on the personal significance of their achievements in generating a cohesive proposal for an underserved community, the value of defence and debate with peers and the importance of using prototyping as proof of concept and for realworld testing. Many also stated that selecting their own problem to work on for the project combined with the real needs of these global communities was a highly motivating factor. Peer review and class collaboration were stated as important attributes of this course, where shared knowledge and discourse formed a part of the class room experience, importantly supporting self-directed learning and only made possible by the studio class format. 
Limitations in defining the authentic learning experiences of the students taking this course were that the analysis was based on project outcomes, student reflections and interviews with staff retrospectively, the data was not collected specifically to investigate learning experiences. What this study suggests is that authentic learning can take place even when the client/user is remote if the elements of course structure, learning activities, assessment practices are combined with a service learning pedagogy and are in place together with a teaching and mentoring approach where the teachers are at critical times 'standing in' for the clients. The degree of authentic experience cannot be measured using the nine elements of authentic learning, however these elements importantly can be used as a reflective and planning framework.

\section{CONCLUSION}

Herrington and Oliver's (2000) framework in describing the attributes for an authentic learning experience provided an insightful basis for reflection on the SRD course. Although this framework is suggested as a pedagogical approach, this paper shows its relevance for reviewing the authenticity of project-based learning. Preparing future ready learners requires new ways for delivering and assessing courses that provide students with experiences requiring higher level learning that can be applied to any complex situation. This study shows that creating authentic learning experiences requires more than just situating projects in real world scenarios, it also involves the crafting of learning activities, class room structures, professional modelling, mentoring and assessment practices to construct an immersive authentic experience.

\section{REFERENCES}

Bissett-Johnson, K. (2014), "Beyond the artefact: developing student awareness of contextual social and environmental sustainability", in Breytenbach, A. and Pope, K., eds., Design with the other 90\%, the Cumulus Johannesburg Conference, South Africa, 22-24 September 2014, Johannesburg, South Africa, Cumulus, pp. 169-181.

Bissett-Johnson, K. (2016), "Big Picture and small picture: learning to design for the user in context”, in Lam, E. and Lee, Y., eds., Open Design for Everything, Hong Kong, Cumulus, pp. 206-210.

Beder, S. (1999), "Beyond technicalities: Expanding engineering thinking", Journal of Professional Issues in Engineering Practice, Vol. 125 No. 1, available: https://doi.org/10.1061/(asce)1052-3928(1999)125:1(12)

Brodeur, D. (2013), "Mentoring young adults in the development of social responsibility", Australasian Journal of Engineering Education, Vol. 19 No. 1, pp. 13-25, available: https://doi.org/10.7158/d12-014.2013.19.1

Cardella, M.E., Zoltowski, C.B. and Oakes, W.C. (2012), "Developing Human-Centered Design Practices and Perspectives Through Service-Learning” Engineering and Social Justice: In the University and Beyond, Baille, C., Pawley, A. and Riley, D. eds, Purdue University Press, West Lafayette, Indian, pp. 11-29.

Design Council, U.K. (2015), The Design Process; What is the Double Diamond?, available: http://www.designcouncil.org.uk/news-opinion/design-process-what-double-diamond [accessed 16 November, 2018].

Herrington, J. and Oliver, R. (2000), "An instructional design framework for authentic learning environments", Educational Technology Research and Development, Vol. 48, pp. 23-48, available: http://dx.doi.org/http://dx.doi.org/10.1007/bf02319856.

Herrington, J., Reeves, T.C. and Oliver, R. (2014), “Authentic Learning Environments” in Spector J., Merrill M., Elen J. and M., B., eds., Handbook of Research on Educational Communications and Technology, New York: Springer, available: http://dx.doi.org/10.4324/9781410609519.

Ideo.org (2015), “The Field Guide to Human-centered Design”, available: https://www.ideo.com/post/design-kit. ISBN: 978-0-9914063-1-9

McDonough, W. and Braungart, M. (2002), Cradle to Cradle, Remaking the way we make things, New York: North Point Press.

Network, H.B. (2018), Honey Bee Network, About Us, available: http://honeybee.org/ [accessed 29 November].

Osterwalder, A., Pigneur, Y. and Clark, T. (2010), Business Model Generation: A Handbook For Visionaries, Game Changers, and Challengers, New Jersey: Willey, John Willey and Sons, available: http://dx.doi.org/10.1111/j.1540-5885.2012.00977_2.x.

Rule, A.C. (2006), “The components of authentic learning”, Journal of Authentic Learning, Vol. 3 No. 1, pp. 1-10.

School, D. (2008), Design Bootleg Bootcamp, DSchool, available: https://dschool.stanford.edu/resources/thebootcamp-bootleg [accessed 29 November 2018].

Strobel, J., Wang, J., Weber, N.R. and Dyehouse, M. (2013), "The role of authenticity in design-based learning environments: The case of engineering education", Computers \& Education, Vol. 64, pp. 143-152, available: https://doi.org/10.1016/j.compedu.2012.11.026 